\title{
Evaluation of intraocular pressure elevation after multiple injections of intravitreal ranibizumab
}

\author{
This article was published in the following Dove Press journal: \\ Clinical Ophthalmology \\ II April 2014 \\ Number of times this article has been viewed
}

\author{
Alice L Yu ${ }^{1, *}$ \\ Florian Seidensticker ${ }^{1, *}$ \\ Markus Schaumberger' \\ Ulrich Welge-Lussen² \\ Armin Wolf' \\ 'Department of Ophthalmology, \\ Ludwig-Maximilians-University, \\ Munich, Germany; ${ }^{2}$ Department of \\ Ophthalmology, Friedrich-Alexander- \\ University, Erlangen, Germany \\ *These authors contributed equally \\ to this work
}

Background: We wanted to determine whether multiple injections of intravitreal ranibizumab was associated with an elevated intraocular pressure (IOP) in patients treated for neovascular age-related macular degeneration (AMD).

Methods: This retrospective study examined 53 patients with neovascular AMD treated with multiple injections of intravitreal ranibizumab. The main outcome measure was the difference in IOP between the frequently-treated study eyes ( $\geq 15$ injections) and the unfrequently-treated fellow control eyes ( $\leq$ five injections). Patients were divided into three study groups: group I (35 patients with 15 to 19 injections); group II (15 patients with 20 to 29 injections); and group III (three patients with $\geq 30$ injections). The IOP was measured by Goldmann applanation tonometry 4 weeks after the last injection of intravitreal ranibizumab. For statistical analysis, the IOP was then correlated with the number of ranibizumab injections.

Results: Among the frequently-treated study eyes, the mean IOP was $13.68 \pm 2.91 \mathrm{mmHg}$ (range, 8 to $20 \mathrm{mmHg}$ ). The unfrequently-treated fellow control eyes had a mean IOP of $13.45 \pm 3.09 \mathrm{mmHg}$ (range, 9 to $25 \mathrm{mmHg}$ ). There was no significant correlation of the IOP difference between the study and control eyes with the number of ranibizumab injections (correlation coefficient $0.77 ; P=0.583$ ). For each of groups I, II, and III, the difference in mean IOP between the study and control eyes was nonsignificant $(P>0.05)$. There was also no significant association of the IOP difference between the study and control eyes with the number of ranibizumab injections for each group $(P=0.391)$.

Conclusion: Our study did not find an increased IOP in frequently-ranibizumab-treated eyes when compared to unfrequently-treated fellow control eyes. Further studies with a greater sample size are needed to evaluate whether an increased number of ranibizumab injections is associated with IOP changes.

Keywords: age-related macular degeneration, ocular hypertension, anti-VEGF therapy

\section{Introduction}

With the introduction of anti-vascular endothelial growth factor (anti-VEGF) antibodies in ophthalmologic therapies, there was a fundamental change in treatment options for various ocular diseases. The indications for anti-VEGF therapy include neovascular age-related macular degeneration (AMD), central vein or branch vein occlusion with macular edema, and diabetic maculopathy. ${ }^{1-3}$ For all indications, an effective therapy with anti-VEGF antibodies can only be achieved by repeated intravitreal anti-VEGF injections.

In general practice, three intravitreal injections of anti-VEGF antibodies are given every 4 weeks in the initial upload phase, followed by further intravitreal injections of anti-VEGF antibodies when a macular edema persists or increases. Therefore, a monthly ophthalmologic checkup is needed to ensure a correct treatment interval with antiVEGF antibodies. Another requirement to allow for frequent anti-VEGF therapy is a
Correspondence: Alice LYu

Ludwig-Maximilians-University,

Department of Ophthalmology,

Mathildenstrasse 8, 80336 Munich,

Germany

Tel +49895I60 38II

Fax +498951605160

Email alice.yu@med.uni-muenchen.de 
low rate of side effects. Until now, various efficacy and safety studies have demonstrated very low rates of side effects after intravitreal anti-VEGF injections. ${ }^{4-6}$ Potential side effects of anti-VEGF therapy include retinal tears, retinal detachment, vitreous hemorrhage, uveitis, or endophthalmitis. ${ }^{7}$

One side effect, which is controversially discussed to be associated with intravitreal anti-VEGF injections, is the rise in intraocular pressure (IOP). ${ }^{8,9}$ While intravitreal steroids are known to be associated with an increased risk for glaucoma, ${ }^{10}$ the data about IOP elevation by anti-VEGF agents such as ranibizumab or bevacizumab are less conclusive, although various pathophysiological mechanisms have been hypothesized for the IOP elevation. On rare occasions, it has been described that the IOP may increase transiently after intravitreal anti-VEGF injections, ${ }^{8,9}$ but returns to baseline level within 30 to 60 minutes without IOP-lowering therapy. ${ }^{11,12}$ This transient IOP elevation may result from variations in scleral rigidity or in reflux from the injection site after withdrawal of the needle. ${ }^{8}$

In the MARINA (Minimal Classic/Occult Trial of the Anti-VEGF Antibody Ranibizumab in the Treatment of Neovascular AMD) and ANCHOR (Anti-VEGF Antibody for the Treatment of Predominantly Classic Choroidal Neovascularisation in AMD) studies, there were no longterm effects on the IOP after treatment with the anti-VEGF antibody ranibizumab. ${ }^{7,13}$ However, a few case studies exist that report an increased risk of sustained IOP elevation after multiple anti-VEGF injections in patients with preexisting glaucoma or ocular hypertension. ${ }^{14,15}$ There are also contradictive results on potential IOP elevation based upon the analysis of the number of intravitreal anti-VEGF injections in nonglaucomatous patients. ${ }^{16,17}$ Indeed, most of these studies compared the IOP changes between patient groups, but not intraindividually. Due to these contradictory observations, we wanted to examine whether multiple injections of intravitreal ranibizumab is associated with a sustained elevated IOP by comparing the IOP of the study eye with that of the fellow control eye of the same subject.

\section{Materials and methods}

We retrospectively examined all patients with neovascular AMD who, between March 2012 and August 2012, were seen and treated with intravitreal ranibizumab by a single retina specialist at the retina service of the eye clinic of the LudwigMaximilians-University, Munich, Germany. Patients' consent was obtained before including their data into this study. This study was performed in accordance with the ethical standards laid down in the 1964 Declaration of Helsinki and approved by the local ethics committee. Patients were included in this study if they had received $\geq 15$ injections of intravitreal ranibizumab in their study eye and $\leq$ five injections of intravitreal ranibizumab in their fellow control eye. This low number of $\leq$ five injections in the fellow control eye was chosen in order to compare the IOP changes after multiple ( $\geq 15$ injections) and few ( $\leq$ five) injections of intravitreal ranibizumab. Patients were excluded from the study if they had preexisting glaucoma or ocular hypertension before the first injection. In addition, patients with uveitis, retina surgery, or local or systemic steroid intake in the past were also excluded. We divided the patients into three different study groups depending on the number of intravitreal injections in their study eye. Patients in group I received 15 to 19 injections, patients in group II received 20 to 29 injections, and patients in group III received 30 or more injections of intravitreal ranibizumab in their study eye.

The IOP was measured by Goldmann applanation tonometry both in the study and in the fellow eye during the follow-up visit 4 weeks after the last injection of intravitreal ranibizumab. For the operation procedure, injection of $0.5 \mathrm{mg}$ ranibizumab was performed at the lower pars plana with a sharp 27-gauge needle after complete sterile draping and rinsing with topical povidone-iodine under topical anesthesia with tetracaine $1 \%$ eye drops. The injection site was located $3.5 \mathrm{~mm}$ posterior to the limbus in pseudophakic eyes, and $4.0 \mathrm{~mm}$ from the limbus in phakic eyes. All additional manipulation, such as the subconjunctival injection of anesthetics or application of pressure by forceps, was avoided. After intravitreal injection, patients were treated with ofloxacin eye drops for 3 days. No steroids were given. No eye received IOP-lowering medications or anterior chamber paracentesis before or after intravitreal injection.

The associations between the IOP levels, the IOP difference between study and control eyes, and the number of intravitreal ranibizumab injections were assessed by Spearman rank correlation, Wilcoxon test, and the Kruskal-Wallis test using SPSS 19.0 software (IBM Corporation, Armonk, NY, USA). Significance was accepted at $P<0.05$. With no previous data available, a sample size calculation was not performed for this retrospective study.

\section{Results}

From a total of 1,240 patients with neovascular AMD who came to our retina service between March 2012 and August 2012, 53 patients fulfilled the inclusion criteria. There were 21 male $(40 \%)$ and 32 female $(60 \%)$ patients with a mean age of $77.4 \pm 7.68$ years (range, 56 to 91 years). The study eyes included 25 right eyes (47\%) and 28 left eyes (53\%). The mean number of injections of intravitreal ranibizumab in 


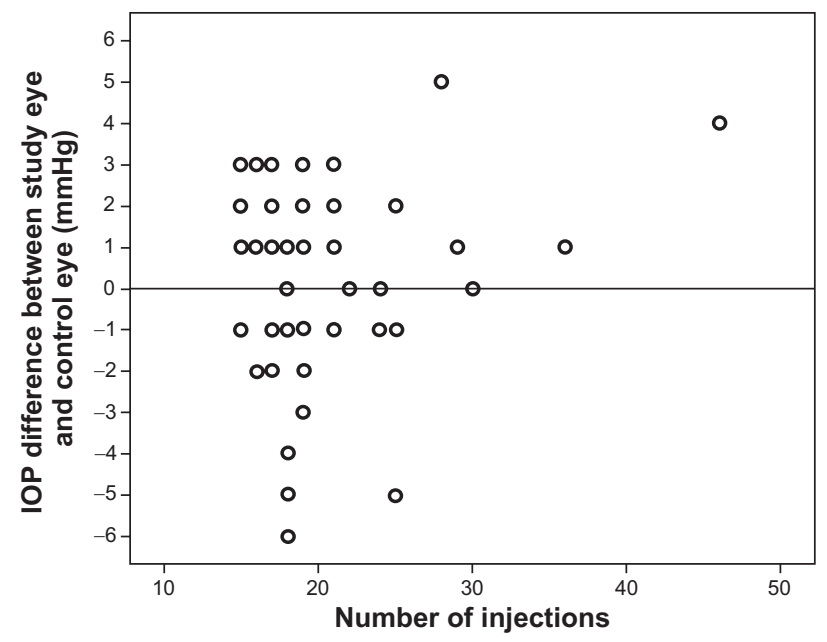

Figure I Correlation of the IOP difference between study and control eyes (in $\mathrm{mmHg}$ ) with the number of intravitreal ranibizumab injections using the Spearman rank correlation.

Abbreviation: IOP, intraocular pressure.

the study eyes was $19.88 \pm 5.82$ (range, 15 to 46 ). The mean IOP of the frequently-treated study eyes was $13.68 \pm 2.91 \mathrm{mmHg}$ (range, 8 to $20 \mathrm{mmHg}$ ) and of the unfrequently-treated fellow control eyes was $13.45 \pm 3.09 \mathrm{mmHg}$ (range, 9 to $25 \mathrm{mmHg}$ ). With the Spearman rank correlation, we compared the IOP difference between the study and control eyes (in $\mathrm{mmHg}$ ) with the number of ranibizumab injections, which did not show any significant correlation (correlation coefficient 0.77 ; $P=0.583$; Figure 1).

In the next step, we divided the patients into groups I, II, and III depending on the number of intravitreal ranibizumab injections they had received (Table 1). Group I (15 to 19 injections) included 35 patients, group II (20 to 29 injections) had 15 patients, and group III ( $\geq 30$ injections) consisted of three patients. In group I, the mean IOP of the study eyes was $13.4 \pm 3.06 \mathrm{mmHg}$ and the mean IOP of the fellow control eyes was $13.49 \pm 3.39 \mathrm{mmHg}$. The mean IOP of the study eyes in group II was $14.13 \pm 2.83 \mathrm{mmHg}$ and of the control eyes was $13.47 \pm 2.74 \mathrm{mmHg}$. Group III had a mean IOP of $17.0 \pm 1.0 \mathrm{mmHg}$ in the study eyes and a mean IOP of $13.67 \pm 2.08 \mathrm{mmHg}$ in the control eyes (Table 1). No study eyes had an IOP increase above $21 \mathrm{mmHg}$ after multiple intravitreal ranibizumab injections (Figure 2).
For each of groups I, II and III, the differences in mean IOP between the study and control eyes (in $\mathrm{mmHg}$ ) were nonsignificant as analyzed by the Wilcoxon test $(P>0.05)$ (Table 1). In total, no significant differences in the changes of IOP between the study eyes and the fellow control eyes were detected. The mean IOP difference between the study eyes themselves (in $\mathrm{mmHg}$ ) of each group also did not show any significant association in the Kruskal-Wallis test $(P=0.554)$.

In addition, we used the Kruskal-Wallis test to assess the relationship of the IOP difference between the study and control eyes (in $\mathrm{mmHg}$ ) with the number of ranibizumab injections in group I, II and III. No significant association was found between the groups ( $P=0.391$; Figure 3$)$.

\section{Discussion}

In this study, we failed to find any significant association between the number of ranibizumab injections and the level of IOP. All patients received between 15 and 46 injections of intravitreal ranibizumab in one eye and $\leq$ five injections in the fellow control eye. None of the 53 patients developed an IOP elevation $>21 \mathrm{mmHg}$ in the study eye 4 weeks after the last injection of intravitreal ranibizumab. Interestingly, there was an increase in the mean IOP from $13.4 \pm 3.06 \mathrm{mmHg}$ in the study eyes of group I (patients with 15 to 19 injections) to $17.0 \pm 1.0 \mathrm{mmHg}$ in the study eyes of group III (patients with 30 or more injections), albeit not statistically significant. However, it must be considered that group III only included three patients while group I had 35 patients. Our results confirmed various other studies which also detected no correlations between anti-VEGF injections and delayed IOP elevation overall. ${ }^{7,13,16,18}$

Until now, few studies have described a sustained IOP elevation after anti-VEGF injections. Bakri et a ${ }^{19}$ was one of the first groups to report on persistent ocular hypertension following intravitreal ranibizumab, in their study of four patients. Adelman et $\mathrm{al}^{20}$ reported a sustained ocular hypertension in $3.45 \%$ of patients after a mean of 13.3 intravitreal bevacizumab and/or ranibizumab injections. In a study of Good et $\mathrm{al}^{21}$ an IOP increase was found in $3.1 \%$ of eyes after a median of 9.5 ranibizumab and/or bevacizumab injections. Choi et a ${ }^{22}$ observed a sustained IOP elevation to $>25 \mathrm{mmHg}$ in $5.5 \%$ of

Table I Mean IOP of the frequently-treated study eyes and the unfrequently-treated fellow control eyes in groups I, II, and III

\begin{tabular}{|c|c|c|c|c|c|}
\hline Group & $\begin{array}{l}\text { Number of ranibizumab } \\
\text { injections }\end{array}$ & $\begin{array}{l}\text { Number of } \\
\text { patients (N) }\end{array}$ & $\begin{array}{l}\text { IOP of the study eyes } \\
\text { (mean } \pm \mathrm{SD}, \mathrm{mmHg} \text { ) }\end{array}$ & $\begin{array}{l}\text { IOP of the control } \\
\text { eyes (mean } \pm \mathrm{SD} \text {, } \\
\mathrm{mmHg} \text { ) }\end{array}$ & $\begin{array}{l}\text { P-value (using } \\
\text { Wilcoxon test) }\end{array}$ \\
\hline I & $15-19$ & 35 & $13.4 \pm 3.06$ & $13.49 \pm 3.39$ & 0.892 \\
\hline II & $20-29$ & 15 & $14.13 \pm 2.83$ & $13.47 \pm 2.74$ & 0.138 \\
\hline III & $\geq 30$ & 3 & $17.0 \pm 1.0$ & $13.67 \pm 2.08$ & 0.5 \\
\hline
\end{tabular}

Abbreviations: IOP, intraocular pressure; SD, standard deviation. 


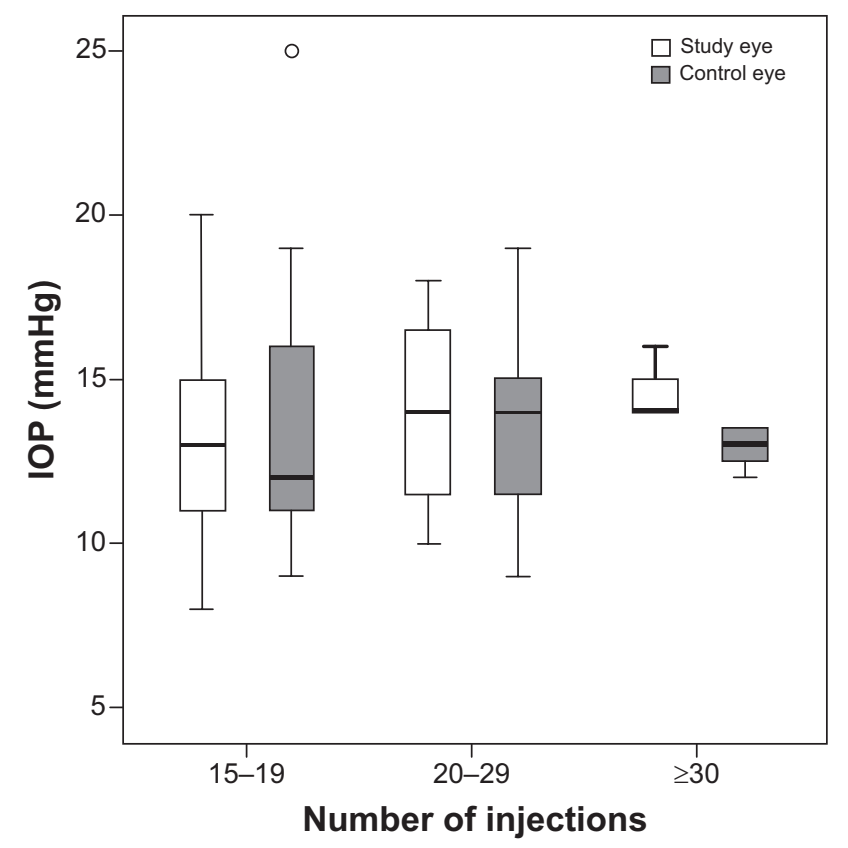

Figure 2 IOP levels (in $\mathrm{mmHg}$ ) of the study eyes and control eyes in each group measured 4 weeks after the last injection of intravitreal ranibizumab.

Notes: The groups were divided according to the number of intravitreal ranibizumab injections received in the study eyes (15-19 injections: group I; 20-29 injections: group II; $\geq 30$ injections: group III).

Abbreviation: IOP, intraocular pressure.

their patients who received an anti-VEGF agent (bevacizumab, ranibizumab, or pegaptanib), and one patient required glaucoma surgery. However, they did not find any association between sustained IOP elevation and the number of intravitreal injections. Of note, none of the patients treated in our study required IOP lowering medication. In contrast to our study, a retrospective analysis of 207 patients found an association between the number of injections of intravitreal ranibizumab

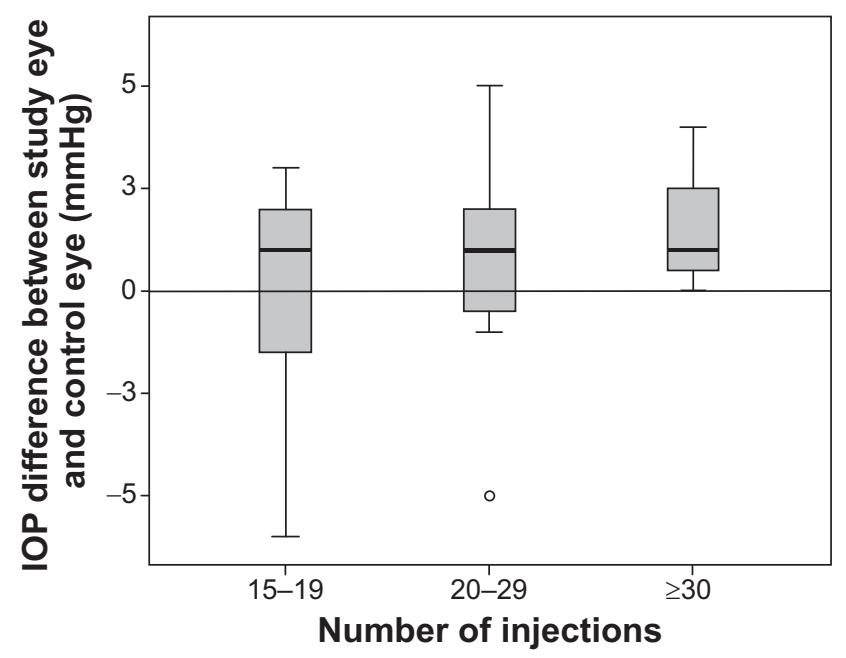

Figure 3 The relationship of the IOP differences between the study and control eyes (in $\mathrm{mmHg}$ ) using the Kruskal-Wallis test.

Notes: Number of intravitreal ranibizumab injections: group I, 15-19 injections; group II, 20-29 injections; and group III, $\geq 30$ injections.

Abbreviation: IOP, intraocular pressure. and/or bevacizumab and an increased risk of IOP elevation to $>5 \mathrm{mmHg}$ on two or more consecutive visits in eyes treated for AMD. ${ }^{23}$ The authors reported that $11.6 \%$ of treated versus $5.3 \%$ of untreated fellow control eyes experienced an IOP increase of $>5 \mathrm{mmHg}$. An increased risk of IOP elevation was found in patients receiving $\geq 29$ injections compared to patients with $\leq 12$ injections. While our data could not confirm that there is an increased IOP for patients with 30 or more injections, we consider it interesting that there was an increased risk of IOP elevation in the groups with a higher number of injections.

There are several hypotheses for the potential mechanisms underlying an IOP increase after anti-VEGF injections. It was assumed that ranibizumab may block the immediate channels, including the trabecular meshwork or Schlemm's canal outflow pathways by an unknown mechanism for several weeks or months. ${ }^{17}$ Another explanation for anti-VEGF-induced IOP elevation is an underlying inflammatory mechanism or an immunological reaction that damages the aqueous humor outflow pathways. ${ }^{24,25}$ Besides that, a traumatic mechanism after frequent injections may lead to a disruption of the anterior hyaloid or zonules and allow access for high molecular weight proteins to enter the anterior chamber, resulting in increased IOP. ${ }^{26}$ It was also reported that different ways of preparing or storing of bevacizumab syringes may also lead to different effects on IOP. ${ }^{27}$ Finally, IOP elevation can also result from leaking of silicone oil particles, which are used to lubricate the components of syringes in the storage of bevacizumab. ${ }^{28}$ In our study, only non-compounded ranibizumab was used, which is considered free of silicone particles. However, we doubt that this could be the sole explanation for a lack of increased IOP as demonstrated in other studies.

In patients with preexisting glaucoma or ocular hypertension, a few reports observed an increased risk of further IOP elevation after anti-VEGF injections. ${ }^{14,15,21}$ Similarly, a predisposition to ocular hypertension along with the sudden increase in intraocular volume can also explain a prolonged increase of IOP. ${ }^{9,29}$ In our study, we did not include patients with a history of glaucoma or ocular hypertension in order to minimize bias. Therefore, further extensive studies are required to analyze whether or not IOP elevation occurs after multiple ranibizumab injections, in particular in glaucoma patients. Additionally, our results are limited by the small sample size in each study group, and we could not perform a sample size calculation. However, due to the bilateral nature of AMD, only a few patients with multiple injections in only one eye could be recruited. Therefore, further multicenter studies with greater sample size would help to verify any association between IOP level and the number of anti-VEGF injections. 
In summary, we could not detect any association between the number of injections of intravitreal ranibizumab and the level of IOP in patients with multiple injections in only one eye. Based on our results, we cannot claim a compelling necessity for postoperative IOP controls after injections of intravitreal ranibizumab. However, with increasing age of the patients with AMD, a regular IOP control is recommended as a trend toward IOP elevation could not be ruled out.

\section{Disclosure}

The authors report no conflicts of interest in this work.

\section{References}

1. Bandello F, De Benedetto U, Knutsson KA, Parodi MB, Cascavilla ML, Iacono P. Ranibizumab in the treatment of patients with visual impairment due to diabetic macular edema. Clin Ophthalmol. 2011;5:1303-1308.

2. Kim M, Yu SY, Kim ES, et al. Intravitreal ranibizumab for macular edema secondary to retinal vein occlusion. Ophthalmologica. 2012;227:132-138.

3. Lala C, Framme C, Wolf-Schnurrbusch UE, Wolf S. Three-year results of visual outcome with disease activity-guided ranibizumab algorithm for the treatment of exudative age-related macular degeneration. Acta Ophthalmol. 2013;91:526-530.

4. Rich RM, Rosenfeld PJ, Puliafito CA, et al. Short-term safety and efficacy of intravitreal bevacizumab (Avastin) for neovascular age-related macular degeneration. Retina. 2006;26:495-511.

5. Gordon-Angelozzi M, Velez-Montoya R, Fromow-Guerra J, et al. Bevacizumab local complications. Ophthalmology. 2009;116:2264e1-3.

6. Fung AE, Rosenfeld PJ, Reichel E. The International Intravitreal Bevacizumab Safety Survey: using the internet to assess drug safety worldwide. Br J Ophthalmol. 2006;90:1344-1349.

7. Brown DM, Kaiser PK, Michels M, et al. Ranibizumab versus verteporfin for neovascular age-related macular degeneration. $\mathrm{N} \mathrm{Engl} \mathrm{J} \mathrm{Med.}$ 2006;355:1432-1444.

8. Bakri SJ, Pulido JS, McCannel CA, Hodge DO, Diehl N, Hillemeier J. Immediate intraocular pressure changes following intravitreal injections of triamcinolone, pegaptanib, and bevacizumab. Eye (Lond). 2009;23:181-185.

9. Kim JE, Mantravadi AV, Hur EY, Covert DJ. Short-term intraocular pressure changes immediately after intravitreal injections of antivascular endothelial growth factor agents. Am J Ophthalmol. 2008; 146:930-934.

10. Kiernan DF, Mieler WF. Intraocular corticosteroids for posterior segment disease: 2012 update. Expert Opin Pharmacother. 2012;13:1679-1694.

11. Hollands H, Wong J, Bruen R, Campbell RJ, Sharma S, Gale J. Short-term intraocular pressure changes after intravitreal injection of bevacizumab. Can J Ophthalmol. 2007;42:807-811.

12. Mojica G, Hariprasad SM, Jager RD, Mieler WF. Short-term intraocular pressure trends following intravitreal injections of ranibizumab (Lucentis) for the treatment of wet age-related macular degeneration. Br J Ophthalmol. 2008;92:584.

Clinical Ophthalmology

\section{Publish your work in this journal}

Clinical Ophthalmology is an international, peer-reviewed journal covering all subspecialties within ophthalmology. Key topics include: Optometry; Visual science; Pharmacology and drug therapy in eye diseases; Basic Sciences; Primary and Secondary eye care; Patient Safety and Quality of Care Improvements. This journal is indexed on Submit your manuscript here: http://www.dovepress.com/clinical-ophthalmology-journal
13. Rosenfeld PJ, Brown DM, Heier JS, et al. Ranibizumab for neovascular age-related macular degeneration. $N$ Engl J Med. 2006;355: 1419-1431.

14. Singh RS, Kim JE. Ocular hypertension following intravitreal antivascular endothelial growth factor agents. Drugs Aging. 2012;29: 949-956.

15. Skalicky SE, Ho I, Agar A, Bank A. Glaucoma filtration surgery following sustained elevation of intraocular pressure secondary to intravitreal anti-VEGF injections. Ophthalmic Surg Lasers Imaging. 2012;43:328-334.

16. Falkenstein IA, Cheng L, Freeman WR. Changes of intraocular pressure after intravitreal injection of bevacizumab (avastin). Retina. 2007; 27:1044-1047.

17. Tseng JJ, Vance SK, Della Torre KE, et al. Sustained increased intraocular pressure related to intravitreal antivascular endothelial growth factor therapy for neovascular age-related macular degeneration. J Glaucoma. 2012;21:241-247.

18. Wehrli SJ, Tawse K, Levin MH, Zaidi A, Pistilli M, Brucker AJ. A lack of delayed intraocular pressure elevation in patients treated with intravitreal injection of bevacizumab and ranibizumab. Retina. 2012; 32:1295-1301.

19. Bakri SJ, McCannel CA, Edwards AO, Moshfeghi DM. Persisent ocular hypertension following intravitreal ranibizumab. Graefes Arch Clin Exp Ophthalmol. 2008;246:955-958.

20. Adelman RA, Zheng Q, Mayer HR. Persistent ocular hypertension following intravitreal bevacizumab and ranibizumab injections. $J$ Ocul Pharmacol Ther. 2010;26:105-110.

21. Good TJ, Kimura AE, Mandava N, Kahook MY. Sustained elevation of intraocular pressure after intravitreal injections of anti-VEGF agents. Br J Ophthalmol. 2011;95:1111-1114.

22. Choi DY, Ortube MC, McCannel CA, et al. Sustained elevated intraocular pressures after intravitreal injection of bevacizumab, ranibizumab, and pegaptanib. Retina. 2011;31:1028-1035.

23. Hoang QV, Mendonca LS, Della Torre KE, Jung JJ, Tsuang AJ, Freund KB. Effect on intraocular pressure in patients receiving unilateral intravitreal anti-vascular endothelial growth factor injections. Ophthalmology. 2012;119:321-326.

24. Sniegowski M, Mandava N, Kahook MY. Sustained intraocular pressure elevation after intravitreal injection of bevacizumab and ranibizumab associated with trabeculitis. Open Ophthalmol J. 2010;4:28-29.

25. Mitchell P, Korobelnik JF, Lanzetta P, et al. Ranibizumab (Lucentis) in neovascular age-related macular degeneration: evidence from clinical trials. Br J Ophthalmol. 2010;94:2-13.

26. Menke MN, Salam A, Framme C, Wolf S. Long-term intraocular pressure changes in patients with neovascular age-related macular degeneration treated with ranibizumab. Ophthalmologica. 2013;229:168-172.

27. Kahook MY, Liu L, Ruzycki P, et al. High-molecular-weight aggregates in repackaged bevacizumab. Retina. 2010;30:887-892.

28. Bakri SJ, Ekdawi NS. Intravitreal silicone oil droplets after intravitreal drug injections. Retina. 2008;28:996-1001.

29. Aref AA. Management of immediate and sustained intraocular pressure rise associated with intravitreal antivascular endothelial growth factor injection therapy. Curr Opin Ophthalmol. 2012;23:105-110.

PubMed Central and CAS, and is the official journal of The Society of Clinical Ophthalmology (SCO). The manuscript management system is completely online and includes a very quick and fair peer-review system, which is all easy to use. Visit http://www.dovepress.com/ testimonials.php to read real quotes from published authors. 